\title{
Measurements of the timescales for the mass transfer of water in glassy aerosol at low relative humidity and ambient temperature
}

\author{
H.-J. Tong ${ }^{1,2}$, J. P. Reid ${ }^{1}$, D. L. Bones ${ }^{1}$, B. P. Luo ${ }^{3}$, and U. K. Krieger ${ }^{3}$ \\ ${ }^{1}$ School of Chemistry, University of Bristol, Bristol, BS8 1TS, UK \\ ${ }^{2}$ Institute for Chemical Physics, Beijing Institute of Technology, Beijing 100081, China \\ ${ }^{3}$ Institute for Atmospheric and Climate Science, ETH Zürich, Zürich, Switzerland
}

Received: 26 January 2011 - Published in Atmos. Chem. Phys. Discuss.: 9 February 2011

Revised: 21 April 2011 - Accepted: 15 May 2011 - Published: 20 May 2011

\begin{abstract}
The influence of glassy states and highly viscous solution phases on the timescale of aerosol particle equilibration with water vapour is examined. In particular, the kinetics of mass transfer of water between the condensed and gas phases has been studied for sucrose solution droplets under conditions above and below the glass transition relative humidity (RH). Above the glass transition, sucrose droplets are shown to equilibrate on a timescale comparable to the change in RH. Below the glass transition, the timescale for mass transfer is shown to be extremely slow, with particles remaining in a state of disequilibrium even after timescales of more than $10000 \mathrm{~s}$. A phenomenological approach for quantifying the time response of particle size is used to illustrate the influence of the glassy aerosol state on the kinetics of mass transfer of water: the time is estimated for the droplet to reach the halfway point from an initial state towards a disequilibrium state at which the rate of size change decreases below $1 \mathrm{~nm}$ every $10000 \mathrm{~s}$. This half-time increases above $1000 \mathrm{~s}$ once the particle can be assumed to have formed a glass. The measurements are shown to be consistent with kinetic simulations of the slow diffusion of water within the particle bulk. When increasing the RH from below to above the glass transition, a particle can return to equilibrium with the gas phase on a timescale of 10's to 100's of seconds, once again forming a solution droplet. This is considerably shorter than the timescale for the size change of the particle when glassy and suggests that the dissolution of the glassy core can proceed rapidly, at least at room temperature. Similar behaviour in the slowing of the mass transfer rate below the glass transition RH is observed for binary aqueous raffinose solution droplets. Mixed component droplets of su-
\end{abstract}

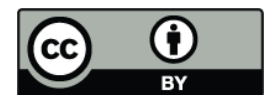

Correspondence to: J. P. Reid (j.p.reid@bristol.ac.uk) crose/sodium chloride/water also show slow equilibration at low RH, illustrating the importance of understanding the role of the bulk solution viscosity on the rate of mass transfer with the gas phase, even under conditions that may not lead to the formation of a glass.

\section{Introduction}

Aerosol particles affect the climate directly by absorbing and scattering radiation (Haywood and Boucher, 2000; Yu et al., 2006) and indirectly by acting as cloud condensation nuclei (CCN) or ice nuclei (IN) (Lohmann and Feichter 2005; Pósfai and Buseck, 2010). They also influence the chemical composition of the atmosphere by acting as sites for heterogeneous chemical reactions (Ravishankara et al., 1997; De Haan et al., 1999). Understanding the dynamic response of aerosols to changes in environmental conditions, such as temperature and relative humidity $(\mathrm{RH})$, is crucial for interpreting the physical and chemical properties of aerosols, including particle phase, hygroscopicity and the partitioning of semi-volatile organic components between the gas and condensed phase (Martin, 2000; Zobrist et al., 2008; Huffman et al., 2009; Pope et al., 2010a and b). These properties are of crucial importance in determining the optical properties of aerosol (Zieger et al., 2010) and their ability to form cloud droplets (for example, Murray et al., 2010; Murray, 2008).

The prompt dissolution of crystalline aerosol into the solution phase at the deliquescence RH (DRH) is wellcharacterised for the dominant inorganic aerosol components found in the atmosphere (Henzler et al., 1993; Tang and Munkelwitz, 1993; Shindo et al., 1997; Dai and Salmeron, 1997; Martin, 2000; Wise et al., 2008). The hysteresis behaviour observed in the mass of condensed phase water

Published by Copernicus Publications on behalf of the European Geosciences Union. 
on reduction of $\mathrm{RH}$ below the deliquescence point is also well established, with a metastable supersaturated solution droplet existing until the efflorescence RH is reached (Martin, 2000; McGraw and Lewis, 2009; Pósfai and Buseck, 2010). With the organic mass fraction of aerosol often representing more than $50 \%$ of the aerosol mass (Reinhardt et al., 2007), the thermodynamic properties of mixed component inorganic/organic aerosol have become a focus for research. The phase behaviour of mixed component aerosol can be highly complex, with changes in the DRH of the inorganic component (Badger et al., 2006; Cruz and Pandis 2000), the phase separation of hydrophobic and hydrophilic domains (Ciobanu et al., 2009), the RH dependent restructuring of particle morphology (Kwamena et al., 2010), and the influence of porosity on the DRH (Mikhailov et al., 2009).

Recently, it has become evident that identifying the formation of metastable amorphous states rather than crystalline phases is crucial for interpreting many measurements of aerosol properties and processes (Virtanen et al., 2010). The formation of glasses, gels, rubbers or highly viscous liquids on drying or cooling is expected to lead to amorphous aerosol (i.e. with no long range molecular order) which may show kinetic limitations when responding to changes in environmental conditions. Numerous inorganic aerosol components (Hoffman et al., 2004; Liu et al., 2008; Zhang et al., 2004; Wang et al., 2005; Tang and Fung, 1997) have been observed to form amorphous phases that do not exhibit prompt deliquescence or efflorescence, and many organic aerosol components are observed to take up or lose water continuously with change in $\mathrm{RH}$, without exhibiting discrete phase transitions (Chan et al., 2005; Prenni et al., 2001; Peng et al., 2001; Mikhailov et al., 2009; Zardini et al., 2008; Lightstone et al., 2000). The low diffusivity of water within an amorphous phase may lead to non-ergodic behaviour, influencing the rate of hygroscopic growth and the activation of $\mathrm{CCN}$ or IN, with the equilibration in size or composition of the aerosol particle occurring on a timescale that is longer than the timescale for the change in environmental conditions. The suppression of ice nucleation in ultra viscous emulsified micron size droplets (Zobrist et al., 2008; Murray et al., 2008) and the slow response to changes in RH for aqueous citric acid-ammonium sulphate droplets (Bodsworth et al., 2010) at low temperature are examples of non-ergodic behaviour. Further, it has been suggested that the high viscosity of amorphous aerosol may inhibit the progress of heterogeneous reactive aging (Mikhailov et al., 2009).

Glasses have found widespread application in numerous areas, including food preservation (Le Meste et al., 2002), drug delivery (Rabinowitz et al., 2006) and the materials industry (Binder and Kob 2005). A glass is a disordered amorphous solid, lacking long range order. Glasses are normally derived by cooling the liquids to below a certain temperature (glass transition temperature, $T_{\mathrm{g}}$ ) or by drying an aqueous solution without crystallization taking place (glass transition relative humidity $\mathrm{RH}_{\mathrm{g}}$ ) (Angell, 1995; Debenedetti and Still- inger, 2001). As the liquid approaches the glass transition, the increase in viscosity leads to a reduced rate of molecular diffusion and an arrested non-equilibrium structure is formed, inhibiting nucleation and the formation of a crystalline solid. The system is restricted in the range of molecular configurations that can be sampled, reducing the likelihood that the system explores a configuration consistent with the thermodynamically stable crystalline state, described as non-ergodic behaviour. The dynamic viscosity of the glass can be in excess of $10^{10} \mathrm{Pas}$, equivalent to that of a typical solid phase (Mikhailov et al., 2009). The glass transition temperature and glass transition relative humidity are dependent on the rate of change of temperature or solute concentration. For example, rapid rates of cooling can lead to a higher value of $T_{\mathrm{g}}$ than slower cooling rates (Debenedetti and Stillinger, 2001; Zobrist et al., 2008). For aerosol particles, the timescale for change in environmental conditions can be expected to be an extremely important factor in influencing the formation of an arrested structure; rapid dehydration may lead to a compositional gradient within a particle and the formation of a highly viscous shell that slows the communication between the particle bulk and surrounding gas phase. Burnett et al. (2004) have reported an increase in $\mathrm{RH}_{\mathrm{g}}$ from 30 to $40 \%$ when spray drying lactose particles at a higher drying rate.

The sensitivity of glass formation and crystallisation to changes in environmental conditions and the dependence on the timescale of coupling between the gas and condensed phases highlights the importance of investigating the properties of glassy aerosol directly (Zobrist et al., 2008; Murray et al., 2008; Bodsworth et al., 2010), rather than relying on bulk solution measurements. In this publication, coarse mode ultra-viscous and glassy aerosol are formed by drying sucrose, raffinose and sucrose-sodium chloride solutions below the glass transition relative humidity. Carbohydrates have been identified in aerosol particles in different continents (Graham et al., 2002; Carvalho et al., 2003; Yttri et al., 2007; Wang et al., 2009). Although the thermodynamic properties and glass transition behaviour of small carbohydrates in solution have been studied extensively (MacKenzie et al., 1977; Orford et al, 1990; Roos 1991, 2010; Champion et al., 1997; Hsu et al., 2003, Frank 2007), only one study has examined directly the formation of glassy aerosol particles through dehydration using an electrodynamic balance (EDB) (Zobrist et al., 2011). In the present work, we compare independent measurements of the formation of glassy sucrose aerosol using aerosol optical tweezers with the previous EDB measurements, confirming the previously reported non-ergodic behaviour accompanying the mass transfer of water between the gas and condensed phases. In addition, we extend this previous work to a further system (raffinose) which exhibits behaviour that is again consistent with the formation of glassy aerosol. Finally, we examine the dependence of the glass formation on the mass fraction of an inorganic solute (sodium chloride). 


\section{Experimental method}

\subsection{Optical tweezers}

A detailed introduction to aerosol optical tweezers and the experimental approach has been described elsewhere (Mitchem and Reid 2008; Wills et al., 2009) and will be only briefly summarized here. A dispersed aerosol mist is generated using a medical nebulizer and introduced into a custom fabricated cell $\left(\sim 8 \mathrm{~cm}^{3}\right.$ in volume). The optical tweezers are arranged in an inverted microscope configuration with an oil immersion microscope objective (numerical aperture of 1.25, $100 \times$ magnification) used to focus the green light generated by a $\mathrm{Nd}: \mathrm{YVO}_{4}(532 \mathrm{~nm})$ laser into the trapping cell, forming a single beam gradient force optical trap. As an aerosol droplet passes close to the laser focus, the gradient force draws the particle into the focus, the region with the largest gradient in light intensity. The gradient force dominates the gravitational and scattering forces by at least two orders of magnitude, providing a strong restoring force that effectively immobilises the particle. A single droplet $(1 \sim 8 \mu \mathrm{m}$ in radius) is captured and held near the beam focus at a height of $\sim 40 \mu \mathrm{m}$ above a thin glass coverslip mounted above the microscope objective. Typical laser powers required are in the range 5 to $15 \mathrm{~mW}$.

By adjusting the balance between flows of dry nitrogen gas and humidified nitrogen gas using needle valves, the $\mathrm{RH}$ in the cell can be regulated. The mass flow rate of each gas is measured by mass flow meters (Bronkhurst, UK). Two capacitance probes are used to monitor the $\mathrm{RH}$ in the gas flow before (probe 1) and after (probe 2) the cell. Once a droplet (sucrose-water, raffinose-water or sucrose-sodium chloridewater) is trapped, the RH in the cell is held at the same value, typically $60 \pm 0.5 \%$, for a couple of hours to allow the droplet and cell to equilibrate to the gas flow. The total gas flow rate is $\sim 0.1 \mathrm{~L} /$ minute and the fluctuation of the temperature for each experiment is $\pm 1 \mathrm{~K}$.

A blue LED $(455 \mathrm{~nm})$ provides illumination for microscopy. Brightfield images are used to observe the morphology of the trapped droplet and the glassy particles that are eventually deposited on the coverslip simply by removing the trapping laser beam. The back scattered Raman light from the droplet is collected using a spectrograph equipped with a 1200 grooves $/ \mathrm{mm}$ grating and imaged onto a CCD array of $1024 \times 256$ pixels. The changing spectra of the droplet are monitored in real time with a time-resolution of $1 \mathrm{~s}$. The spontaneous Raman spectrum provides a signature of the composition of the droplet. The stimulated Raman spectrum, occurring at wavelengths commensurate with whispering gallery modes (WGMs), is used to characterize the size of the droplet (Mitchem and Reid, 2008; Wills et al., 2009). The wavelengths of the WGMs are dependent on the size of the droplet and by comparing these wavelengths with predictions from the Mie scattering theory, the droplet size can be determined with nanometer accuracy.

\subsection{The refractive index and density of aqueous sugar solutions}

The refractive indices of sucrose, raffinose and mixed component (sucrose with sodium chloride) solutions with different concentrations were measured at $\lambda=589 \mathrm{~nm}$ using a Palm Abbe PA203 digital refractometer (MISCO, USA) at a constant temperature of $298 \pm 1 \mathrm{~K}$. Each refractive index value is determined from an average of 3 individual measurements. The measured refractive indices as a function of solute molarity are shown in Fig. 1 for the aqueous sucrose and raffinose binary solutions. Measurements for the sucrose solution agree well with published data (International Organization of Legal Metrology,1993) and fall close to values estimated from a volume fraction mixing rule. To estimate the volume fraction values, the average of the refractive index for the fast and slow axes for birefringent crystalline sucrose (1.558) is taken as the crystalline value (Halbout, 1982). A polynomial fit to the experimental data is used to estimate the refractive index at intermediate molarities. Above the highest measured concentration (a refractive index of 1.504 at $\sim 3.7 \mathrm{M}$ ), there is uncertainty in the refractive index value. As discussed in section III.a, this leads to uncertainty in the refractive index at RHs below $40 \%$. However, even at the highest of solution concentrations when approaching a mass fraction of solute of 1 , the value estimated from the polynomial fit lies below the crystalline value by only 0.0093 or $0.6 \%$, equivalent to an uncertainty in the size estimate which remains less than $20 \mathrm{~nm}$ for all of the measurements reported here at RHs below $40 \%$. Indeed, as we shall see later, the time dependence of size below this RH becomes the important parameter for investigation rather than the absolute value of the size, and the kinetic measurements of size change are not compromised by inaccuracies in the refractive index treatment.

The polynomial fit is used to estimate the variation in refractive index with solute molarity and, thus, droplet size from knowledge of the droplet composition and size at the initial RH at which the droplet size is allowed to equilibrate (Wills et al., 2009). This enables Mie predictions of the WGM wavelengths with variation in trial particle size and the retrieval of the droplet size from each unique recorded fingerprint of WGM wavelengths. Although this is based on measurements at $589 \mathrm{~nm}$ and the WGM fingerprints are centred around $650 \mathrm{~nm}$, the variation with wavelength over this range is considerably less than the variation with solute concentration. Thus, correctly representing the variation in refractive index with droplet size/solute concentration is crucial for estimating the particle size from the WGM fingerprint. Neglecting dispersion, the wavelength dependence, introduces an error to the size of $<10 \mathrm{~nm}$ (Hanford et al., 2008).

The densities of sucrose solutions of different concentrations can be estimated from the assumption of the volume additivity of pure component densities (VAD), allowing the density to be estimated from the densities of water, $\rho_{\mathrm{w}}$ (taken 

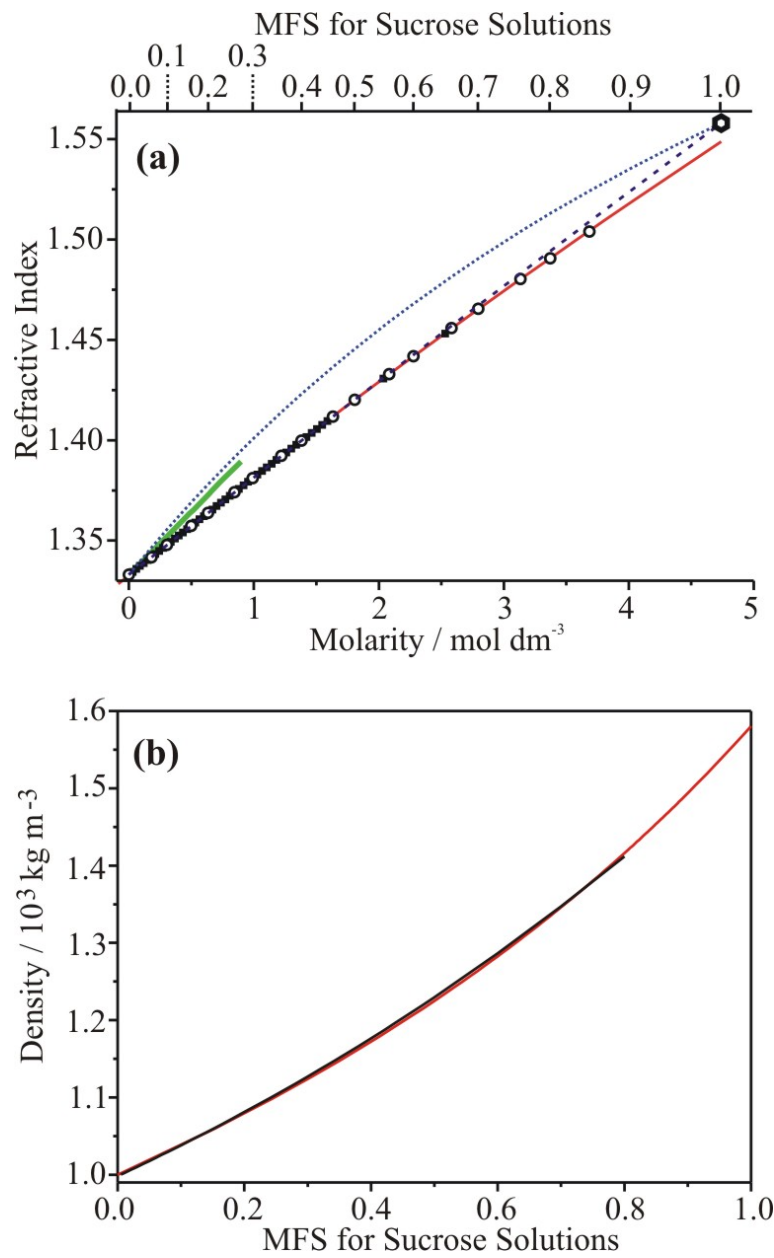

Fig. 1. (a) Refractive index as a function of the solute molarity and mass fraction of solute (MFS) for aqueous sucrose solutions: black squares, these measurements; open circles, literature data; red line, polynomial fit; dashed blue line, volume fraction mixing rule; dotted blue line, mass fraction mixing rule; hexagon, value taken as crystalline refractive index from Halbout and Tang (1982). A parameterised fit to the measured values for aqueous raffinose solution are shown by the green line. (b) Dependence of sucrose solution density on solute molarity: black line, literature data (Haynes, 2011); red line, volume additivity model.

as $1000 \mathrm{~kg} / \mathrm{m}^{-3}$ ), and sucrose, $\rho_{\mathrm{s}}$ (taken as $1580.5 \mathrm{~kg} / \mathrm{cm}^{-3}$, Haynes, 2011), and the mass fraction of solute (MFS):

$\frac{1}{\rho}=\frac{1-\mathrm{MFS}}{\rho_{\mathrm{w}}}+\frac{\mathrm{MFS}}{\rho_{\mathrm{s}}}$

This treatment yields values that compare well with published data (Haynes, 2011) over the range up to an MFS of 0.9 , as shown in Fig. $1 b$.

\section{Predictions of the equilibrium and time-dependent size of glassy sucrose particles}

\subsection{Sucrose droplets at equilibrium}

The prediction of the equilibrium size or mass of an aqueous aerosol particle at a particular RH containing an involatile organic, such as sucrose, requires knowledge of the composition of the solution at thermodynamic equilibrium with the gas phase, the density of the solution at the equilibrium composition $\left(\rho_{\text {wet }}\right)$, and the mass of solute $\left(m_{\text {Dry }}\right)$ or diameter of the equivalent dry solute particle $\left(D_{\text {Dry }}\right)$. The dependence of the wet droplet diameter $\left(D_{\mathrm{w}}\right)$ on RH can be conveniently expressed as a diameter growth factor $\left(\mathrm{GF}_{\mathrm{dia}}(\mathrm{RH})\right)$,

$\mathrm{GF}_{\mathrm{dia}}(\mathrm{RH})=\frac{D_{\mathrm{w}}}{D_{\text {Dry }}}=$

$\left(\frac{m_{\mathrm{w}} \rho_{\text {Dry }}}{m_{\text {Dry }} \rho_{\text {wet }}}\right)^{1 / 3}=\mathrm{GF}_{\text {mass }}(\mathrm{RH})^{1 / 3}\left(\frac{\rho_{\text {Dry }}}{\rho_{\text {wet }}}\right)^{1 / 3}$

where $m_{\mathrm{w}}$ is the mass of the solution droplet, $\rho_{\text {Dry }}$ is the density of the pure dry solute and $\mathrm{GF}_{\text {mass }}(\mathrm{RH})$ is the mass growth factor. The mass growth factor can be estimated from a thermodynamic parameterisation of the equilibrium mass fraction of solute in the solution droplet at a specific water activity, such as those presented in Fig. 2a. The diameter growth factor can then be calculated and compared directly with the optical tweezers measurements, in which the varying droplet size with RH is measured.

Numerous experimental studies have measured the dependence of the water activity of aqueous sucrose solutions on the weight percentage of solute in solution, commonly referred to as the mass fraction of solute, MFS. These measurements are shown in Fig. 2a and are compared with four parameterisations (Norrish, 1966; Starzak and Peacock, 1997; Zobrist et al., 2008). The dependence of the glass transition temperature on the MFS in solution reported in previous publications is shown in Fig. 2b, indicating that a glass transition should occur as the MFS increases above 0.95 at room temperature.

Norrish (1966) suggested a relationship of the water activity, $a_{\mathrm{w}}$, of nonelectrolyte solutions to the mole fractions of water and solute, $x_{\mathrm{w}}$ and $x_{\mathrm{s}}$, respectively:

$a_{\mathrm{w}}=x_{\mathrm{w}} \exp \left(k x_{s}^{2}\right)$

$k$ is an empirical constant estimated to be -6.47 for sucrose (Labuza, 1984). The applicability of this value has been confirmed to extend to high solute concentrations by recent measurements (Baeza et al., 2010).

Starzak and Peacock (1997) provided a comprehensive fit to the experimental data using the Margules equation for the water activity coefficient, $\gamma_{\mathrm{w}}$, with

$\ln \gamma_{\mathrm{w}}=\frac{Q}{R T}\left(x_{s}^{0}\right)^{2}\left[1+b_{1} x_{s}^{0}+b_{2}\left(x_{s}^{0}\right)^{2}\right]$ 

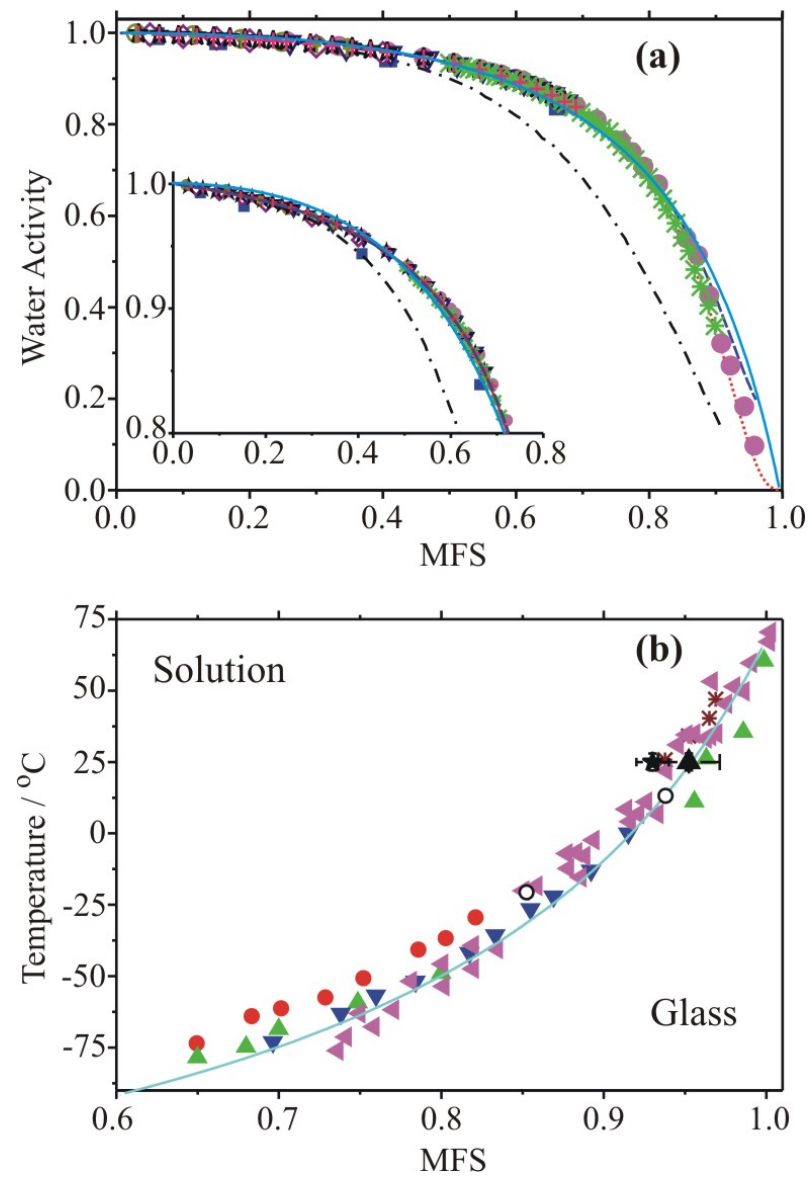

Fig. 2. (a) Water activity as a function of the mass fraction of solute (MFS) from the ADDEM model (dotted dashed black line), and the parameterisations of Norrish (1966, dotted red line), Zobrist et al. (2008, light blue line) and Starzak and Peacock (1997, dashed blue line) for the sucrose solution. Experimental data is shown by the symbols: crosses, Scatchard et al. (1938); stars, Robinson and Stokes (1965); squares, Chuang et al. (1976); down triangles, Rüegg and Blanc (1981); diamonds, Lerici et al. (1983); filled circles, Bressan and Mathlouthi (1994); asterisks, Bubnik et al. (1995); and open circles, Mogenson et al. (2009). The inset shows an expanded range above a water activity of 0.8 . (b) The glass transition temperature as a function of MFS from previous publications and the present study. For the present study, the composition at the glass transition has been estimated from the water activity and either the Norrish water activity/MFS relationship (black star) or the Starzak and Peacock relationship (black triangle). Literature values: open black circles, Koster 1991; red circles, Ablett et al., 1992; green triangles, Roos 1993; brown asterisks, Blanshard et al., 1991; blue triangles, Franks 1993; purple triangles, Sun et al., 1996; light blue line, Hsu et al., 2003.

where $x_{s}^{0}$ is the nominal mole fraction of sucrose, and $Q=$ $-17538 \mathrm{~J} \mathrm{~mol}^{-1}, b_{1}=-1.0038$ and $b_{2}=-0.24653$. From the activity coefficient estimate from Eq. (4) at a specific mole fraction of solute, the water activity can be estimated, and is shown in Fig. 2a.
A further parameterisation of experimental data has been described by Zobrist et al. (2011). The water activity is expressed as a function of the MFS in the form

$$
\begin{aligned}
& a_{\mathrm{w}}=\frac{1+a \cdot \mathrm{MFS}}{1+b \cdot \mathrm{MFS}+c \cdot \mathrm{MFS}^{2}}+ \\
& \left(T-T^{\Theta}\right)\left(d \cdot \mathrm{MFS}+e \cdot \mathrm{MFS}^{2}+f \cdot \mathrm{MFS}^{3}+g \cdot \mathrm{MFS}^{4}\right)
\end{aligned}
$$

where $a=-1, b=-0.99721, c=0.13599, d=0.001688$, $e=-0.005151, f=0.009607$ and $g=-0.006142$, and $T^{\Theta}$ is the reference temperature $298.15 \mathrm{~K}$. This expression is valid over the temperature range 160 to $313 \mathrm{~K}$ and the entire concentration range.

In previous optical tweezers measurements we have compared the change in equilibrium droplet size with RH for mixed inorganic/organic aerosol with the Aerosol Diameter Dependent Equilibrium Model, ADDEM (Topping et al., 2005; Hargreaves et al., 2010; Hanford et al., 2008.). The treatment of organic components in this model is based on the widely used group contribution method UNIFAC. The variation in water activity with solute concentration calculated from this treatment is also presented in Fig. 2a.

For the binary water-sucrose system, it is clear that the water activity is underestimated by ADDEM at a sucrose MFS greater than 0.35 when compared with the experimental data. The Norrish parameterisation represents the experimental data most accurately over the whole RH range. The Starzak and Peacock and Zobrist treatments deviate from the experimental data at water activities below 0.5. The latter treatment has been shown to accurately describe the change in equilibrium properties of aqueous sucrose droplets examined in EDB measurements (Zobrist et al., 2011) and is the treatment used for the kinetic simulations described below.

The mass growth factor can be estimated, with variation in water activity, from the expression:

$\mathrm{GF}_{\text {mass }}(\mathrm{RH})=\frac{m_{\mathrm{w}}}{m_{\text {Dry }}}=\frac{1}{\mathrm{MFS}}$

The variations in the mass growth factors estimated from the four treatments are shown in Fig. 3a. From the VAD treatment of density and the mass growth factors reported in Fig. 3a, the RH dependence of the diameter growth factor can be estimated from Eq. (2), and the predictions are presented in Fig. 3b. The differences between growth factor predictions from the Norrish, Zobrist and ADDEM treatments reflect the differences in the water activity/MFS relationships discussed above. Only the Norrish and Zobrist treatments will be compared with the experimental data presented below. The Norrish treatment is chosen as it provides the most accurate reflection of the solution thermodynamics. The Zobrist treatment is chosen as the second model for comparison with the experimental data as it provides the underpinning treatment of solution thermodynamics for the kinetic model described below. 

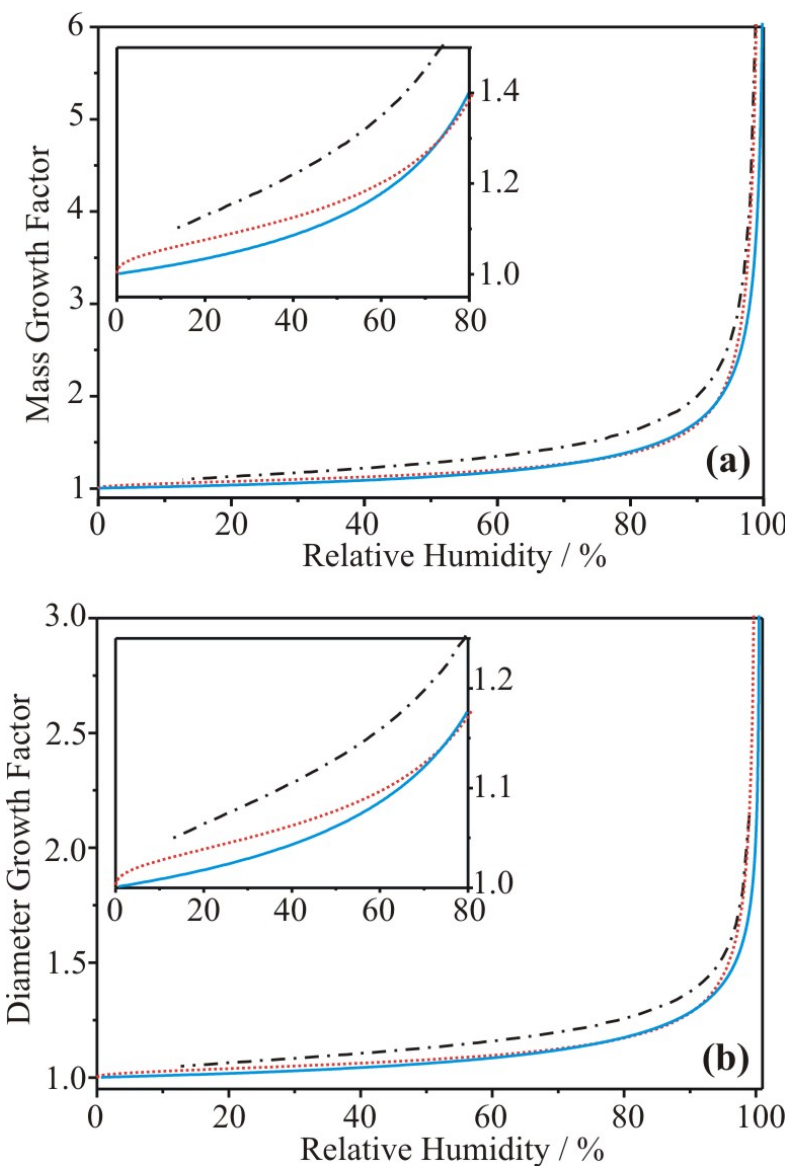

Fig. 3. (a) Mass growth factors as a function of relative humidity based on the water activity data parameterisations of Norrish (dotted red line), ADDEM (dash dot black line) and Zobrist (light blue line) for sucrose aerosol. (b) Diameter growth factors for the same treatments (same colours) as (a) using the volume additivity treatment of density for sucrose aerosol.

\subsection{The time-dependent size of glassy sucrose droplets}

Previously, Zobrist et al. (2011) have shown that the water uptake kinetics in sucrose droplets far from thermodynamic equilibrium can be modelled by solving the spherical diffusion equation. The crucial point is that the diffusivity of water inside the particle becomes a function of the water concentration itself, which renders the diffusion equation non-linear and difficult so solve. A numerical spherical shell diffusion model has been developed, which shows that the diffusion profiles of water into a highly viscous sucrose particle leads to steep diffusion "fronts" instead of the widely known creeping diffusion tails (Marshak, 1985). The temperature dependence of $D_{\mathrm{H}_{2} \mathrm{O}}$ is parameterized according to a Vogel-Fulcher-Tammann (VFT) approach (Debenedetti and Stillinger, 2001) and thus $D_{\mathrm{H}_{2} \mathrm{O}}$ is parameterized as:

$\log _{10}\left[D_{\mathrm{H}_{2} \mathrm{O}}\left(T, a_{\mathrm{w}}\right)\right]=-\left(A\left(a_{\mathrm{w}}\right)+\frac{B\left(a_{\mathrm{w}}\right)}{T-T_{0}\left(a_{\mathrm{w}}\right)}\right)$
$A, B$ and $T_{0}$ are fit functions that all depend on the water activity of the aqueous sucrose solution, which in itself is also a function of the temperature and concentration. The fit equations for the three parameters, $A, B$, and $T_{0}$ are given in Zobrist et al. (2011). The relationship between the MFS and the water activity is provided by the Zobrist parameterisation described in Sect. 3.1.

\section{Formation and hygroscopicity of single glassy sucrose particles at room temperature}

Either rapid cooling or drying at a constant temperature enhances the likelihood of glass formation over nucleation and crystallisation (Angell, 1995; Debenedetti and Stillinger, 2001). In the measurements presented here, we have chosen to rapidly dry a trapped aerosol droplet by switching between a humidified gas flow at an RH above $60 \%$ to a completely dry flow of nitrogen gas with an RH approaching $0 \%$ at constant temperature. The glass transition $\mathrm{RH}$ is $\sim 24 \%$ at the temperature of the measurements presented here $(298 \pm 2 \mathrm{~K})$. An example of the recorded change in $\mathrm{RH}$ and droplet size is presented in Fig. 4a for a sucrose-water droplet (initially with a MFS of $\sim 0.3)$. After a period of $\sim 7200 \mathrm{~s}(\sim 2 \mathrm{~h})$ held at an RH of $66 \%$ to allow the wet aerosol to equilibrate to a size of $4300 \mathrm{~nm}$, the humidified wet $\mathrm{N}_{2}$ flow was switched to a full dry $\mathrm{N}_{2}$ flow to rapidly dry the droplet, reducing the $\mathrm{RH}$ in the cell to $<10 \%$ in less than $25 \mathrm{~s}$. Notably, the release of water from the droplet persisted for more than $18000 \mathrm{~s}$ $(5 \mathrm{~h})$. After $72000 \mathrm{~s}(20 \mathrm{~h})$, the RH was varied in increasing or decreasing steps while restricting it to below the glass transition relative humidity, expected to occur at $\sim 24 \%$ at $298 \mathrm{~K}$ (Fig. 2b). Once again, the droplet radius responded very slowly to the changes in RH over a period of 7000 to $10000 \mathrm{~s}(\sim 2$ to $3 \mathrm{~h})$ and size changes of less than $10 \mathrm{~nm}$ were recorded for each $5 \%$ change in $\mathrm{RH}$ with the droplet never achieving an equilibrium size (Fig. 4b).

The variations in equilibrium size of the sucrose droplet with RH predicted by the Norrish and Zobrist parameterisations are shown in Fig. $4 a$ and $b$ for comparison. The observed droplet radius is offset from the Norrish and Zobrist predictions by $\sim 4$ and $\sim 15 \mathrm{~nm}$, respectively, at the lowest RH $(<1.5 \%)$ after $72000 \mathrm{~s}(20 \mathrm{~h})$, well within the expected limits set by the uncertainties in the refractive index and RH. Agreement with the ADDEM predictions is worse with the offset $>180 \mathrm{~nm}$, as anticipated from Fig. 2. These results suggest strongly that the droplet has passed through a glass transition on drying and that a disequilibrium is established between the droplet and the surrounding vapour phase which persists for more than $18000 \mathrm{~s}(5 \mathrm{~h})$ and is only very slowly approached.

After $147600 \mathrm{~s}(41 \mathrm{~h})$, the laser trap was removed allowing the particle to deposit onto the glass coverslip. Images were obtained by gradually raising the focal depth of the image plane for the brightfield image and laser focus from below to 

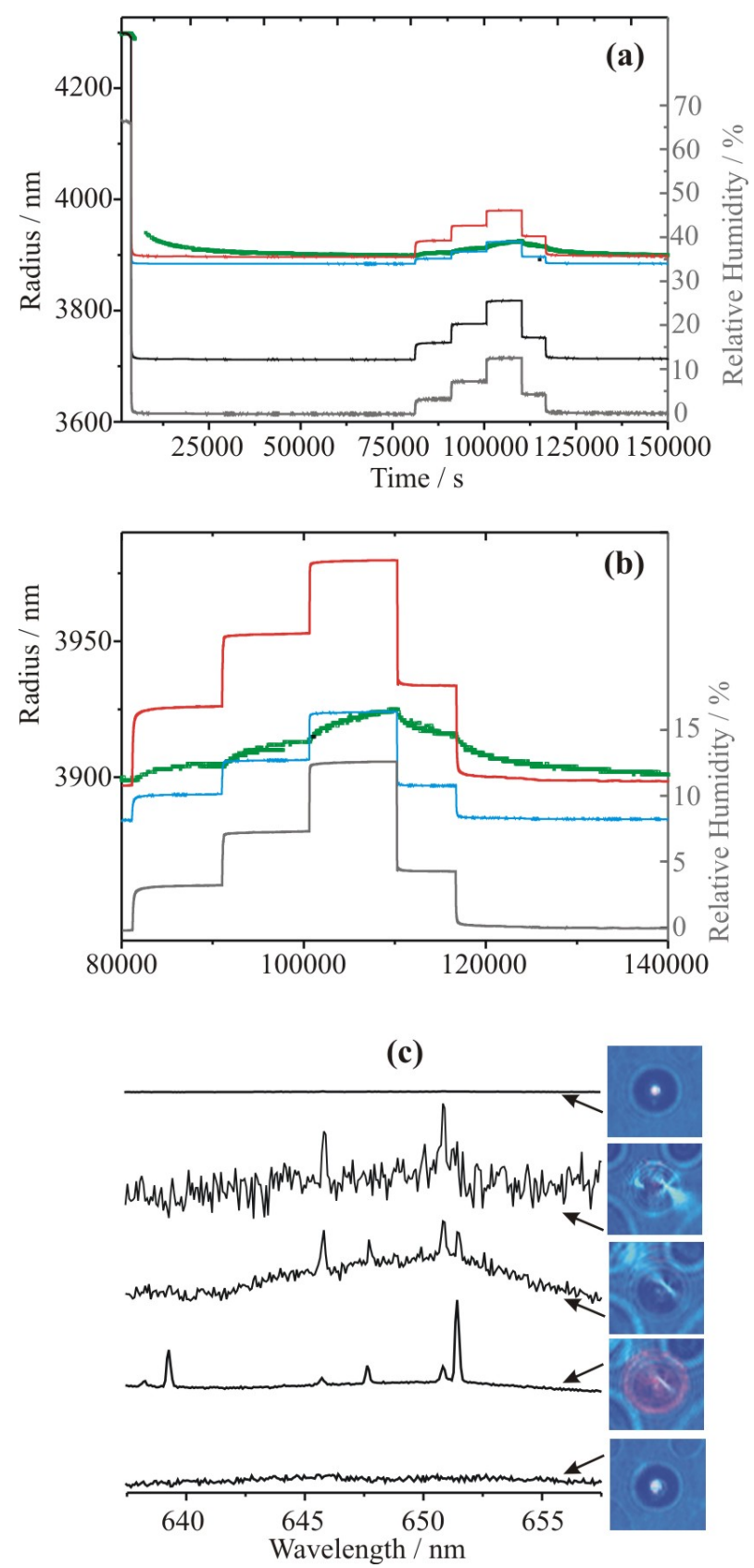

Fig. 4. (a) Time-dependence of the size of a sucrose droplet (green) with change in $\mathrm{RH}$ (grey line, right axis). The sizes predicted at equilibrium using the Norrish (red line), Zobrist (light blue line) and ADDEM (black line) thermodynamic models are shown for comparison. The rapidly changing size cannot always be determined from measurements at early time following the sudden decrease in $\mathrm{RH}$ due to the rapid translation in WGM wavelengths. This gives rise to the broken time-record of measured size at times of $\sim 10000$ s. (b) Same as for (a) but showing expanded view around 100000 s. (c) Final images and Raman spectra of the glassy sucrose particle when deposited on the coverslip and with varying image height. From top to bottom: laser focus below the coverslip, at the bottom surface of the particle, at the middle of the particle, at the top surface of the particle and above the particle. above the droplet, Fig. 4c. The Raman spectra corresponding to each image are also shown in the region of the $\mathrm{OH}$ stretching vibration of water (Mitchem and Reid, 2008; Wills et al., 2009). Although the laser beam was reintroduced prior to recording the images and Raman spectra, it was not possible to remove the particle optically from the coverslip. Not only does the particle appear to retain a spherical morphology on sedimentation to the coverslip from the brightfield image, but the presence of strong WGM enhanced Raman scattering in the spectra when the particle is illuminated confirms that the particle remains spherical (Mitchem and Reid 2008; Wills et al., 2009). Release of a liquid solution droplet to the coverslip always results in spreading and the loss of sphericity. These observations strongly suggest that the particle has formed an amorphous solid or glass. The $\mathrm{OH}$ Raman stretching signature confirms that considerable water is retained within the particle even though the $\mathrm{RH}$ is considerably less than $10 \%$. The formation of crystalline hydrates cannot be ruled out at this stage, but the data presented below are consistent with the formation of a glassy state. Although Fig. 4 provides strong evidence for the formation of a glassy sucrose aerosol particle and a kinetically imposed limit on size, finer steps in $\mathrm{RH}$ are required to determine the glass transition RH and to compare the accuracy of the thermodynamic models for representing the size above and below the glass transition. An example of a sucrose droplet subjected to smaller transitions in RH is presented in Fig. 5a. For comparison with the model predictions, the droplet is assumed to be in equilibrium at the highest water activity/RH. Predictions from the Norrish equilibrium treatment and the kinetic model based on the Zobrist water activity parameterisation are shown. The kinetic simulations are based on the diffusion constants for water in glassy sucrose particles measured in EDB studies (Zobrist et al., 2011). Although qualitatively in agreement, the shallow slope of the growth factor at intermediate RHs from the Norrish parameterisation (Fig. 3b) leads to an overestimate of the measured size by up to $25 \mathrm{~nm}$. This cannot be accounted for by the uncertainty associated with the RH measurement, $\pm 2 \%$.

At RHs above the glass transition, the agreement between the kinetic model and measurements is excellent, both in absolute size and temporal dependence. For each transition in $\mathrm{RH}$, the droplet approaches an equilibrium size at long times that is consistent with that predicted from the Zobrist parameterisation to within $8 \mathrm{~nm}$. Below the glass transition, the discrepancy in size becomes larger, but remains less than $20 \mathrm{~nm}$ at all RHs and times. This is well within the uncertainty expected from the uncertainty in composition and, thus, refractive index at low water activity, as discussed in Sect. 2.2.

A comparison of the temporal dependencies of size measured and predicted from the kinetic model is presented in Fig. $5 \mathrm{~b}$ for four of the transitions in RH shown in Fig. 5a: 43 to $36.7 \%, 26$ to $16.3 \%, 6.6$ to $0 \%$ and 45.6 to $1.6 \%$. The discontinuous appearance of the measured droplet size is simply a consequence of the choice to perform the fitting 


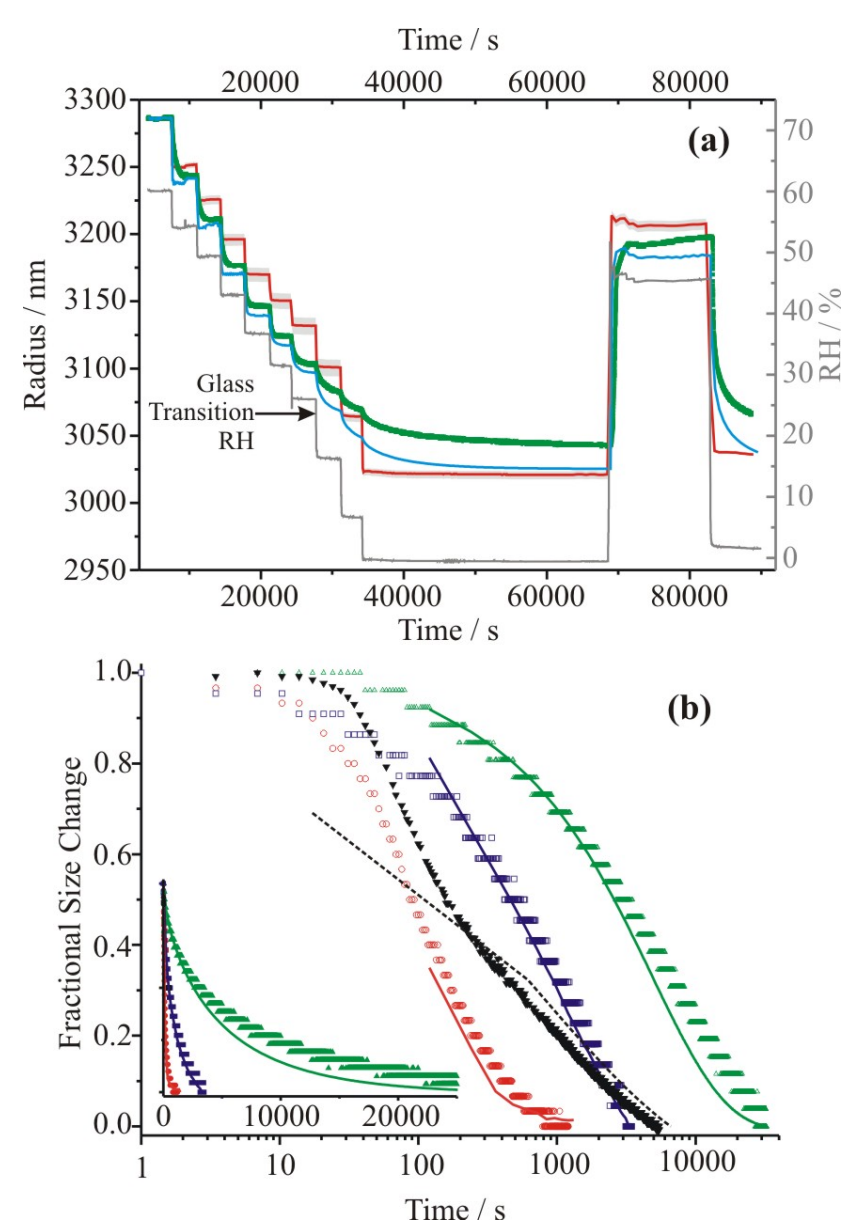

Fig. 5. (a) Time-dependence of the size of a sucrose droplet (green) with change in RH (grey line, right axis). The predicted equilibrium size using the Norrish (red line) model is shown for comparison along with the kinetic model (light blue) which uses the Zobrist parameterisation for water activity. The grey shaded envelope surrounding the Norrish predictions reports the uncertainty in the model based on the uncertainty in the experimentally determined $\mathrm{RH}$ of $\pm 2 \%$. (b) Comparison of the time-response of droplet size for four of the RH changes reported in part (a): red, 43 to $36.7 \%$; blue, 26 to $16.3 \%$; green, 6.6 to $0 \%$; black, 45.6 to $1.6 \%$. The experimental data is shown by the symbols and the results of the kinetics simulations by the lines.

of the WGM fingerprint with a trial size step of $1 \mathrm{~nm}$. While the linear time scale shown in the inset demonstrates the clear slowing in the rate of mass transfer as the glass transition is approached and then passed, the log scale in the main figure more clearly highlights the exceptional degree of agreement between the kinetic model and measurements. The kinetic model reproduces the observed change in timescale of more than 2 orders in magnitude for RH transitions above and below the glass transition. Notably, even though the glass transition is not surpassed for the 43 to $36.7 \%$ RH change, the droplet still takes up to $1000 \mathrm{~s}$ to fully equilibrate, reflecting that even at this relatively high $\mathrm{RH}$, the viscosity of the

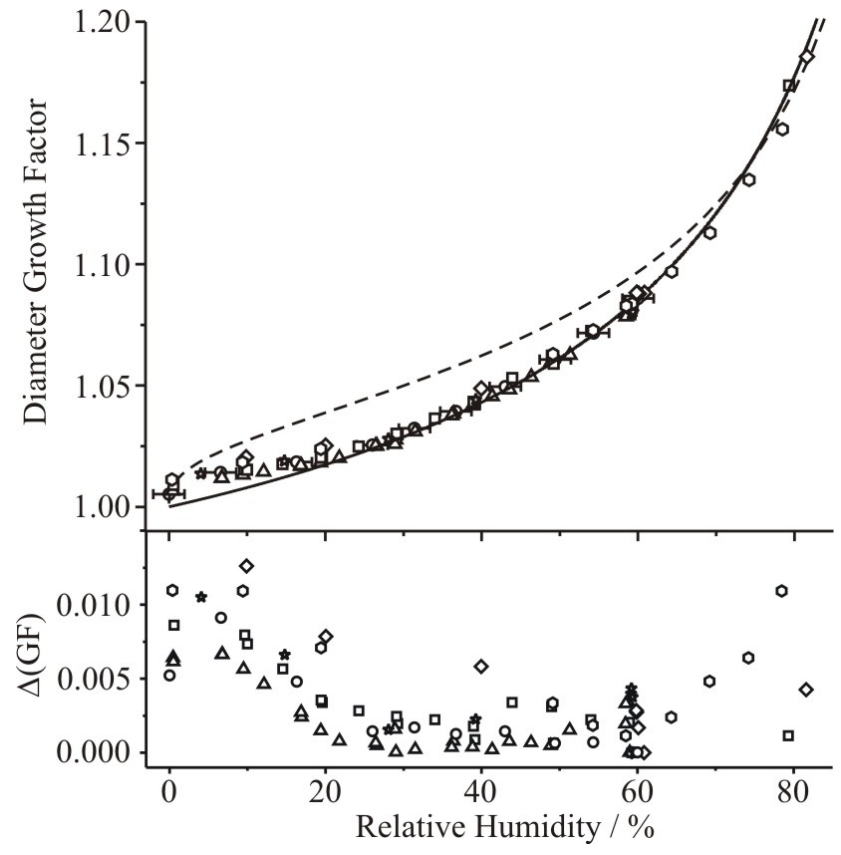

Fig. 6. A comparison of the measured $\mathrm{RH}$ variation in diameter growth factor after $\sim 5000 \mathrm{~s}$ of equilibration with the Zobrist (solid line) and Norrish (dashed line) model predictions of the equilibrium state. Measurements made on different droplets (6 in total) are shown by different symbols. Although the Zobrist parameterisation is quantitatively more consistent with the measured data at high RH, the systematic departure from equilibrium behaviour after $\sim 5000$ s of equilibration with decreasing $\mathrm{RH}$ is apparent. The lower panel shows $\Delta(\mathrm{GF})=\mid \mathrm{GF}$ (measured)-GF(Zobrist) $\mid$. Uncertainties in the RH measurements are shown at the $\pm 2 \%$ level for one experiment.

droplet and diffusion within the bulk of the particle still limit mass transfer. We shall return to a discussion of the correlation with viscosity in Sect. 5. For the change in RH from 45.6 to $1.6 \%$ considered in Fig. 5 b, the temporal dependence of size is considerably different from that observed for the events that involve a smaller change in RH. In fact, the size change takes longer to initiate and this may be a consequence of a very rapid dehydration of the droplet surface, dropping the water activity below the glass transition, and forming a relatively impermeable shell around the droplet surface. This is a clear indication of the effect of different conditions and drying rate on particle size.

Estimating a timescale for droplets to adapt to change in environmental conditions above and below the glass transition would be extremely helpful for qualitatively assessing the change in rate of mass transfer as a droplet approaches a glassy state. However, care must be taken in assessing the time response of the glassy aerosol: it is not clear that equilibrium is reached even on a timescale longer than $20000 \mathrm{~s}$. In Fig. 6 we compare the apparent diameter growth factor measured after $5000 \mathrm{~s}$ to the Zobrist and Norrish equilibrium 

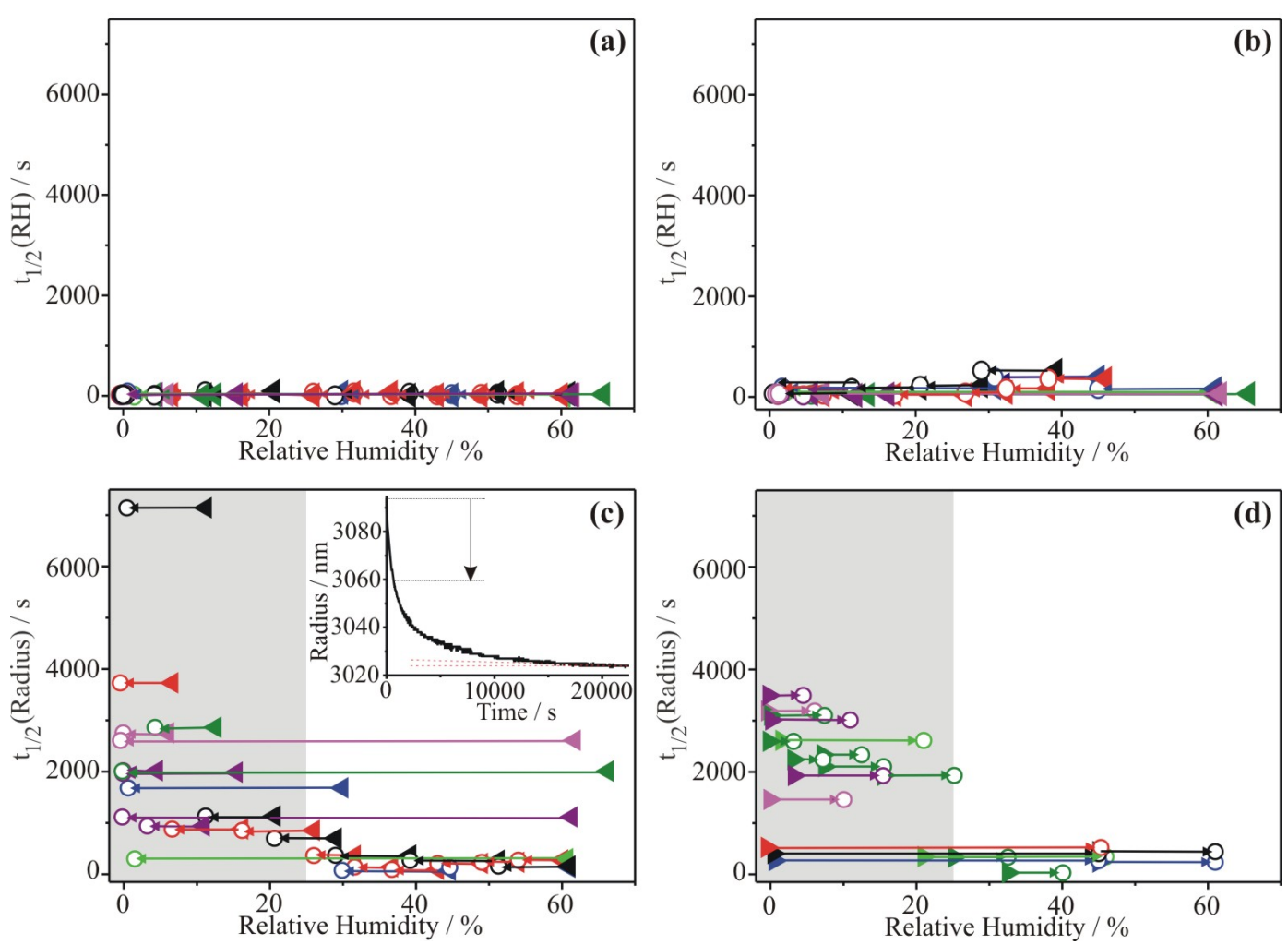

Fig. 7. The recorded half-time for the RH decrease before (a) and after (b) the trapping cell. The filled triangles denote the initial RH and the open circles the final RH with different colours corresponding to measurements on different droplets. (c) The half-time estimated for the change in sucrose droplet radius for a series of dehumidifying measurements on different droplets (different colours). The grey shaded area indicates the RH region which is considered to lie below the glass transition. The inset is an example of a typical size measurement. After $10000 \mathrm{~s}$, the rate of decrease in size becomes less than $1 \mathrm{~nm}$ in $10000 \mathrm{~s}$, as illustrated by the red dotted line. The time for the droplet to reach the half way point in progressing to this slowly evolving size provides a measure of the change in the rate of mass transfer below the glass transition. (d) The half-time for increase in radius of sucrose droplets during a humidifying cycle.

state predictions. While it is clear that the Zobrist parameterisation more accurately reflects the equilibrium state at RHs above $25 \%$, it is clear that there is increasing divergence as the $\mathrm{RH}$ is lowered, strongly suggesting that equilibrium is not achieved on a timescale of $5000 \mathrm{~s}$, as shown in the error plot in the lower panel. This does, however, amount to an offset of $<0.01$ in GF from the Zobrist parameterisation, or $<1 \%$ in size.

From Figs. 4 and 5, a comparatively fast initial decrease (or increase) in size after an RH change is followed by extremely slow evaporation (or growth) and size changes of less than $1 \mathrm{~nm}$ over $10000 \mathrm{~s}$. We use this rate as a criterion for defining an effective plateau in the particle size. Then, the time for the droplet size to decrease to the halfway point in its progress to this plateau can be used to compare the response time of the droplet to changes in RH above and below the glass transition. Even if the measurements were prolonged for a further $50000 \mathrm{~s}$, this would lead to a further decrease in size that was less than $10 \%$ of the overall size change, with little impact on the reported timescale for the droplet to progress to the halfway point. In many applications, the behaviour on extremely long timescales ( $>20000 \mathrm{~s})$ is much less relevant than the behaviour over the 100 to $1000 \mathrm{~s}$ timescale. The half-time provides a phenomenological guide as to the time-response of the droplet size, clearly signalling the onset of glassy behaviour.

The variations in the half-time recorded for the change in the $\mathrm{RH}$ reading from the probes before (probe 1) and after (probe 2) the cell are shown in Fig. 7a and b, respectively. The time-response of probe 2 provides a control measurement of the time lag for the whole flow system to reach the conditions set by the input gas flow and recorded by probe 1. It is noticeable that although the response of the pre-cell probe 1 is limited by the slow time-response of the capacitance RH probe, some changes in RH do take longer to achieve for the whole flow system. Despite this, it is clear that the timescale for the aerosol size-response, made for numerous droplets, is systematically and significantly slower than the RH probes once the final $\mathrm{RH}$ is below the glass transition at $\sim 24 \% \mathrm{RH}$ (Fig. 7c). All measurements were made at a temperature of $298 \pm 2 \mathrm{~K}$. The marked slowing of the size change when conditions take the aerosol below the 
glass transition highlights the significant retardation in mass transfer between the particle bulk and vapour phase once the glass is formed. No sudden loss of water is observed that would signify crystallisation; instead the aerosol vitrifies and becomes glassy and the mobility of water molecules is inhibited although not suppressed entirely.

The half-times recorded during the humidifying process are shown in Fig. 7d. Again, particles existing in a glassy state show resistance to water transport and equilibration. The water adsorption remains controlled by bulk diffusion and the rate of permeation of water into the bulk of the glassy aerosol. Once the final RH with which the particle is equilibrating increases above the glass transition $\mathrm{RH}$, the water adsorption and dissolution of the glass becomes more rapid, although the rate noticeably remains higher than would be expected based on the timescale of the RH change. It is clear from Fig. 5a and $b$ that increasing the RH above the glass transition returns the droplet to equilibrium with the gas phase on a timescale of 10's to 100's of seconds, considerably shorter than changes that lead to the formation or maintain a glassy state. This suggests that the ultraslow diffusion of water in the glass may not be the kinetic parameter limiting particle size change once water is able to adsorb to the particle surface and dissolution of the glassy core can proceed towards an equilibrium solution state.

The solute mass fractions at which the tweezers measurements suggest the glass transition occurs (at $298 \pm 2 \mathrm{~K}$ ) are indicated in Fig. 2b, with the Norrish treatment of water activity yielding a solute mass fraction of 0.93 and the Stazark and Peacock treatment a value of 0.95 . The values are in excellent agreement with previous measurements, confirming once again that the aerosol behaviour is consistent with the formation of a glassy particle. Using the model prediction by He et al. (2006), the viscosities of sucrose-water solutions with sucrose mass fractions of 0.93 and 0.95 are $\sim 10^{9}$ and $\sim 10^{13} \mathrm{~Pa}$ s, respectively. This suggests that the Stazark and Peacock (1997) thermodynamic treatment is better able to predict the glass transition of sucrose aerosol rather than the Norrish treatment; $10^{12} \mathrm{Pas}$ is a typically accepted viscosity value for a glass transition (Debenedetti and Stillinger, 2001).

Based on the diffusion constant prediction curve by $\mathrm{He}$ et al. (2006), the water diffusion coefficient is $\sim 10^{-19} \mathrm{~m}^{2}$ $\mathrm{s}^{-1}$ in the $95 \%$ sucrose mass fraction solution at $20^{\circ} \mathrm{C}$. Figure $5 \mathrm{~b}$ suggests that the diffusion constant reported by Zobrist et al. (2011) and used in the kinetic simulation, $\sim 8 \times 10^{-16} \mathrm{~m}^{2} \mathrm{~s}^{-1}$ at this temperature and composition, may be too large; the experimental size changes more slowly than predicted for all three of the small steps in RH. This requires further investigation to assess the accuracy of the value of the diffusion constant that has been reported by Zobrist et al. (2011) and used in the simulation of the aerosol optical tweezers measurements. Using the diffusion constant of $\mathrm{He}$ et al. (2006), a water molecule would require more than 2.8 years to diffuse to the surface from within a 3 micron radius

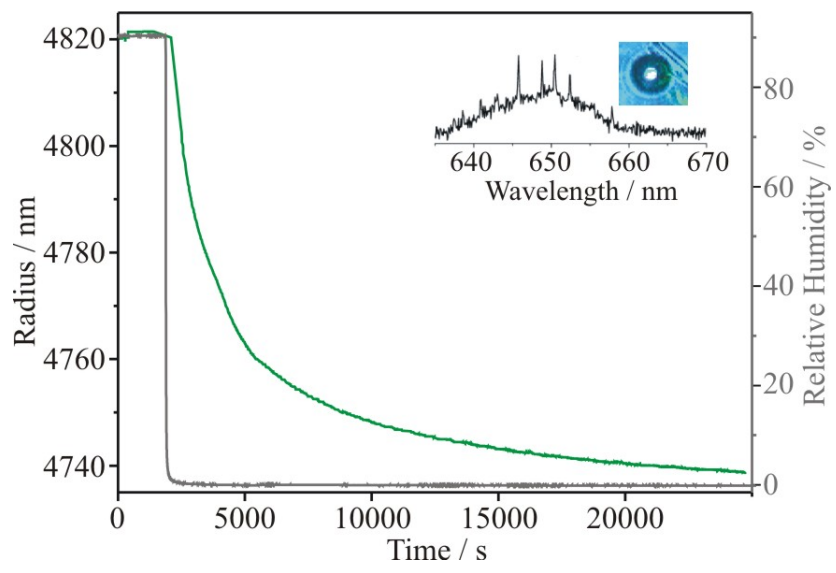

Fig. 8. The time dependence of the size of a raffinose droplet (green line) and the relative humidity of the gas flow entering the trapping cell (grey line, right axis). The inset shows the image of the particle and a Raman spectrum when deposited on the coverslip after $25000 \mathrm{~s}$.

droplet below the glass transition. Thus, a fully equilibrated sucrose droplet below the glass transition would be expected to be unobservable on the timescale of our experimental measurements.

\section{Formation of glassy raffinose particles and mixed component sucrose/sodium chloride particles at room temperature}

To provide further evidence of the influence of a glass transition on the timescale for mass transfer between the condensed and gas phases, the time-response of droplets containing a higher molecular weight carbohydrate, raffinose $\left(\mathrm{C}_{18} \mathrm{H}_{32} \mathrm{O}_{16}\right)$, has been investigated. After equilibrating at $\sim 89 \% \mathrm{RH}$ for more than $7200 \mathrm{~s}(2 \mathrm{~h})$, the $\mathrm{RH}$ in the cell was suddenly decreased to fully dry conditions $(<5 \% \mathrm{RH})$, Fig. 8, by switching instantaneously from a humidified nitrogen to dry nitrogen flow. Water desorption from the raffinose-water droplet persisted even after $21600 \mathrm{~s}$ (6h). As for the sucrose measurements, the concentration of raffinose in the droplet at the starting RH was estimated from the water activity parameterisation provided by Zobrist et al. (2008), allowing the refractive index to be estimated for determination of the starting size. According to Zobrist et al. (2008), raffinose passes through the glass transition at an $\mathrm{RH}$ of $\sim 53 \%$ at room temperature. Thus, the influence of a glassy state on the mass transfer reported in Fig. 8 is expected and crystallization is inhibited. After $21600 \mathrm{~s}(6 \mathrm{~h})$, the particle was deposited on the coverslip. A brightfield image and Raman spectrum of the particle is shown in the inset to Fig. 8. As for sucrose, the particle retains a spherical shape when deposited on the coverslip, which is apparent from the persistence of WGMs on the $\mathrm{OH}$ water Raman band; this also 
indicates that water is retained within the particle. Notably, raising the $\mathrm{RH}$ above the glass transition $\mathrm{RH}$ led to the dissolution of the deposited particle.

To consider the significance of the length of the equilibration timescale for atmospheric aerosol, it is important to consider the influence of internally mixed inorganic components such as sodium chloride on the time response of the aerosol to change in environmental conditions. As a typical soluble organic chemical with many hydroxyl groups, sucrose is able to form strong hydrogen bonds with water. The addition of sodium chloride, recognised as a structure breaking solute in aqueous solution (Mitchem et al., 2006) can be expected to have a significant impact on the hydrogen bonding network in the aqueous sucrose droplets, hence influencing physical properties such as viscosity and the glass transition temperature.

Measurements of the half-time for the equilibration of mixed component sucrose/sodium chloride were performed with a varying solute mole fraction of sodium chloride. In each measurement, the droplet was first conditioned at an $\mathrm{RH}$ of $78 \%$ for $\sim 10000 \mathrm{~s}(\sim 3 \mathrm{~h})$, the RH was then abruptly decreased to below $2 \% \mathrm{RH}$ and the response of the particle size was recorded. The ratio of the half-time for the droplet size change to the change in the $\mathrm{RH}$ measured by probe 1 is presented in Fig. 9a with variation in composition. Uncertainties in these ratios of half-times are based on measurements from numerous droplets with the same composition. The ratio was observed to decrease from $\sim 150$ to $\sim 45$ when the mole fraction of sodium chloride increased from 0 to 0.2 . This indicates that the addition of $\mathrm{NaCl}$ significantly decreases the timescale for mass transfer with the surrounding vapour, enhancing the release of water, although the rate remains slow.

To interpret the compositional measurements for equilibration timescales shown in Fig. 9a, it is necessary to consider the change in viscosity with change in mole fractions of the two solutes. Chenlo et al. (2002) examined the dependence on composition of the kinematic viscosity and density of aqueous mixtures of sucrose and sodium chloride over the molality range 0 to $4.5 \mathrm{~mol} \mathrm{~kg}^{-1}$ for both solutes and at temperatures between 293 and $323 \mathrm{~K}$. They also reported parameterisations based on solute molality and temperature that yielded the measured densities and kinematic viscosities for the ternary solutions within $\pm 0.5 \%$ and $\pm 3 \%$, respectively. The dynamic viscosity ( $\mathrm{Pa} \mathrm{s}$ ) can be estimated from the density $\left(\mathrm{kg} \mathrm{m}^{-3}\right)$ and kinematic viscosity $\left(\mathrm{m}^{2} \mathrm{~s}^{-1}\right)$. For a sucrose solution with a MFS of 0.94 , the dynamic viscosity can be estimated to be $6 \times 10^{12} \mathrm{~Pa}$ s from the treatment of Chenlo et al., which compares well with the values estimated from the treatment of He et al. (2006), even though the molality at this MFS $\left(38.8 \mathrm{~mol} \mathrm{~kg}^{-1}\right)$ is considerably above the highest concentration measurement on which the parameterisation is based. Given that the sucrose component dominates the determination of the viscosity for the mixture, this gives some confidence in the use of the Chenlo et al. (2002) parameterisations at higher solute molalities than $4.5 \mathrm{~mol} \mathrm{~kg}^{-1}$.
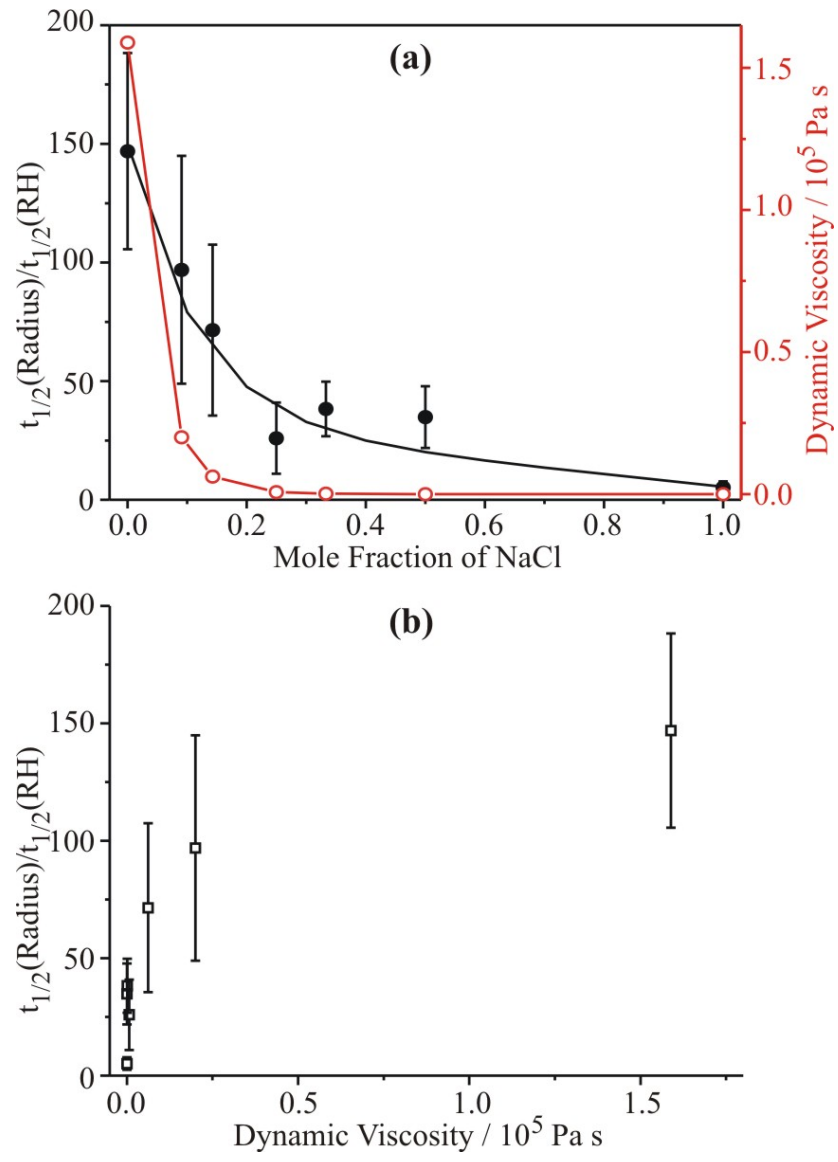

Fig. 9. (a) The composition dependence of the ratio of the halftimes for the radius to the RH changes (black circles) for aqueous sodium chloride/sucrose droplets. The composition dependence of the dynamic viscosity at a solution composition with water activity of 0.4 is also shown (red circles, right axis). (b) Dependence of the half-time ratio shown in (a) on solution viscosity.

Ignoring the non-ideal effects that are likely to play a role at low RH, the water content of the ternary solution can be estimated by applying the Zdanovski-Stokes-Robinson mixing rule and the compositions of binary solutions. Specifically, the total water content, $W(\mathrm{~kg})$, can be written as

$W=\frac{M_{\mathrm{NaCl}}}{m_{\mathrm{NaCl}, 0}\left(a_{\mathrm{w}}\right)}+\frac{M_{\text {Sucrose }}}{m_{\text {Sucrose }, 0}\left(a_{\mathrm{w}}\right)}$

where $M_{i}$ is the number of moles of solute $i$ and $m_{i, 0}\left(a_{\mathrm{w}}\right)$ is the molality of the binary solution at the water activity $a_{\mathrm{w}}$. Experimental data for sodium chloride solutions extends down to a water activity of 0.4 (Clegg, 1997), and the composition of sucrose solutions below this water activity is also uncertain (Fig. 2). Given this, we have chosen this water activity (RH) at which to estimate the solution composition and the dynamic viscosity, shown in Fig. 9a. At this water activity, the molalities of sodium chloride and sucrose in the binary component solutions are 15.9 and $23.6 \mathrm{~mol} \mathrm{~kg}^{-1}$. Although not fully reflecting the dynamic viscosity under the 
conditions at which the glassy aerosol is likely to form, it is clear that the change in equilibration half-time and bulk viscosity show similar behaviour (Fig. 9b). The water activity is likely to be inhomogeneous within an evaporating ternary droplet and it is not surprising that considering the viscosity at one water activity alone (in the middle of the $\mathrm{RH}$ range during the RH drop being studied) fails to capture effectively the microscopic nature of the dynamics. However, the increasing timescale for equilibration with decreasing $\mathrm{RH}$ and increasing bulk viscosity is consistent with the gradual change in equilibration timescale as the glass transition is approached and surpassed in the single component sucrose aerosol measurements. Further studies of the dependence of the timescale for mass transfer on particle composition are essential.

\section{Conclusions}

We have described observations of the influence of a glass transition on the kinetics of mass transfer in the equilibration of water between the condensed and gas phases of aqueous sucrose, raffinose and sodium chloride/sucrose aerosol. Once the aerosol particle has formed a glass, the particle may remain at disequilibrium for timescales far longer than $5000 \mathrm{~s}$ reflecting the extremely low diffusivity of water within the glass. The measured time-dependence of particle size compares well with kinetic predictions (Zobrist et al., 2011), providing independent verification of the impact of a glass transition on the water evaporation or condensation rate. When deposited on a glass coverslip, the particle retains a spherical shape, confirmed by the persistence of WGMs on the $\mathrm{OH}$ Raman band signature. Not only have the kinetic limitations imposed on mass transfer by the glassy state been considered for single-component organic aerosol, but a delay in mass transfer is observed for mixed component aerosol containing sodium chloride, with the time constant for the size change showing a correlation with bulk viscosity.

Kolb et al. (2010) have reviewed the current understanding of the uptake of gaseous phase molecules by an aerosol particle, separating out the limitations associated with surface accommodation (adsorption) and bulk accommodation (absorption), and highlighting the considerable uncertainty in even interpreting measurements of the condensation or evaporation of water (Miles et al., 2010). The measurements presented here are consistent with a slow diffusion rate for water in the bulk of the particle leading to the slow rate of mass transfer between the condensed and gas phases. This could be interpreted as implying a low value for the bulk accommodation coefficient, although reducing the problem to one value for this coefficient is probably over simplistic. It is also apparent that a low value for the surface accommodation/evaporation coefficient cannot be ruled out and could also lead to significant kinetic limitation being imposed on mass transfer. However, assigning the observed mass trans- fer impedance to an accommodation coefficient alone would mean a drastic change of this accommodation coefficient with solute concentration. While it is widely accepted that viscosity and diffusivity change strongly with solute concentration, there is no indication for a similar effect in the accommodation coefficient.

The measurements presented here and by Zobrist et al. (2011) have been made on coarse mode particles of radii greater than $\sim 3 \mu \mathrm{m}$. An important issue to address is the relevance of these measurements to ambient atmospheric particles consisting of complex chemical mixtures and with a size in the accumulation mode. For example, while it has been inferred that ambient accumulation mode particles can exist in a glassy state (Virtanen et al., 2010), the timescale for water transport to and from such particles remains ill-defined. While the analysis presented here does not provide a comprehensive framework with which to assess the kinetic limitations imposed on ambient atmospheric aerosol particle size when existing in glassy or amorphous states, it is possible to establish some guidelines as to what must be considered.

1. The kinetic limitation imposed on water transport between the gas and condensed phases is primarily associated with the diffusion constant in the particle bulk and is not simply related to the existence of a glass. This is shown both by the delayed time-response of particles even when above the glass transition RH and by the correlation of time-response with bulk viscosity for the mixed sucrose-sodium chloride aerosol. Although the kinetic limitations may be most severe at low temperatures, it is not simply an issue of bulk diffusion slowing mass transport at low temperatures. It is essential to assess the dependence of the viscocity/diffusion coefficients of water in aerosol as a function of composition, water activity and temperature.

2. The time-response of aerosol particle size and composition to environmental change is dependent on the time history of RH and temperature. For example, slow changes in RH experienced by a particle will lead to a different response in the kinetically limited size than more rapid changes. This will require considerable further investigation.

3. While it is likely that accumulation mode particles rich in organic components will approach the equilibrium state on a timescale considerably shorter than coarse mode particles, the framework provided by Zobrist et al. (2011) shows that the relationship between the square root of time and particle size cannot be assumed, as would be derived from a simple Einstein relationship. Again, considerable further investigation is required.

4. The time-response of particle size and composition observed here when the RH is increased to a value above 
the glass transition $\mathrm{RH}$ suggests that the process of humidification may lead to more rapid changes in particle size than would be expected from the low diffusion constants for water penetrating into the core of a glassy particle. The kinetics of size change are likely to be dependent on the rate of dissolution into a low viscosity aqueous shell that is at equilibrium composition with the surrounding water activity.

5. It has been common to assume that the properties of aerosol measured in studies using flow tubes, HTDMAs, EDBs etc. (e.g. hygroscopic growth) are governed by aerosol that exists in an equilibrium state. Although this is most likely the case for many measurements, determining the kinetic response of aerosol in any instrument is fraught with complications and the role of kinetic factors in limiting measured properties cannot often be entirely excluded.

While we do not consider that the measurements presented here and in Zobrist et al. (2011) represent a panacea for understanding the kinetic limitations imposed on water transport between the gas and condensed aerosol phases, they do indicate the importance of considering kinetic limitations further, particularly through controlled laboratory measurements.

Acknowledgements. JPR acknowledges the support of the EPSRC through the award of a Leadership Fellowship. H.-J. Tong acknowledges the Chinese Scholarship Council for funding. Yun-Hong Zhang, Allen Haddrell and Graham Hargreaves are acknowledged for helpful discussions.

Edited by: G. McFiggans

\section{References}

Ablett, S., Izzard, M. J., and Lillford, P. J.: Differential Scanning Calorimetric Study of Frozen Sucrose and Glycerol Solutions, J. Chem. Soc. Faraday Trans., 88(6), 789-794, 1992.

Angell, C. A.: Formation of Glasses from Liquids and Biopolymers, Science, 267, 1924-1935, 1995.

Badger, C. L., George, I., Griffiths, P. T., Braban, C. F., Cox, R. A., and Abbatt, J. P. D.: Phase transitions and hygroscopic growth of aerosol particles containing humic acid and mixtures of humic acid and ammonium sulphate, Atmos. Chem. Phys., 6, 755-768, doi:10.5194/acp-6-755-2006, 2006.

Baeza, R., Pérez, A., Sánchez, V., Zamora, M. C., and Chirife, J.: Evaluation of Norrish's Equation for Correlating the Water Activity of High Concentrated Solutions of Sugars, Polyols, and Polyethylene Glycols, Food Bioprocess Technol., 3, 87-92, 2010.

Binder, K. and Kob, W.: Glassy materials and disordered solids: An introduction to their statistical mechanics, World Scientific Publishing Company, 2005.

Blanshard, J. M. V., Muhr, A. H. and Gough, A.: Water Relationships in Foods-Advances in the 1980s and Trends in the 1990s, Plenum Press, New York, USA, p. 639, 1991.
Bodsworth, A., Zobrist, B., and Bertram, A. K.: Inhibition of efflorescence in mixed organic-inorganic particles at temperatures less than $250 \mathrm{~K}$, Phys. Chem. Chem. Phys., 12, 12259-12266, 2010.

Bressan, C. and Mathlouthi, M.: Thermodynamic activity of water and sucrose and the stability of crystalline sugar, Zuckerindustrie, 119, 652-658, 1994.

Bubnik, Z., Kadlec, P., Urban, D., and Bruhns, M.: Sugar technologists manual, Berlin, Germany, Dr. Albert Bartens, 162 pp. 1995.

Burnett, D. J., Thielmann, F., and Booth, J.: Determining the critical relative humidity for moisture-induced phase transitions, Int. J. Pharm., 287, 123-133, 2004.

Carvalho, A., Pio, C., and Santos, C.: Water-soluble hydroxylated organic compounds in German and Finnish aerosols, Atmos. Environ., 37, 1775-1783, 2003.

Champion, D., Hervet, H., Blond, G., Le Meste, M., and Simatos, D.: Translational Diffusion in Sucrose Solutions in the Vicinity of Their Glass Transition Temperature, J. Phys. Chem. B., 101, 10674-10679, 1997.

Chan, M. N., Choi, M. Y., Ng, N. L., and Chan, C. K.: Hygroscopicity of Water-Soluble Organic Compounds in Atmospheric Aerosols: Amino Acids and Biomass Burning Derived Organic Species, Environ. Sci. Technol., 39, 1555-1562, 2005.

Chenlo, F., Moreira, R., Pereira, G., and Ampudia, A.: Viscosities of aqueous solutions of sucrose and sodium chloride of interest in osmotic dehydration processes, J. Food Eng., 54, 347-352, 2002.

Chuang, L. and Toledo, R. T.: Predicting the water activity of multicomponent systems from water sorption isotherms of individual components, J. Food Sci., 41, 922-927, 1976.

Ciobanu, V. G., Marcolli, C., Krieger, U. K., Weers, U., and Peter, T.: Liquid-Liquid Phase Separation in Mixed Organic/Inorganic Aerosol Particles, J. Phys. Chem. A., 113, 10966-10978, 2009.

Clegg, S. L., Brimblecombe, P., Liang, Z., and Chan, C. K.: Thermodynamic Properties of Aqueous Aerosols to High Supersaturation: II A Model of the System $\mathrm{Na}^{+}-\mathrm{Cl}^{-}-\mathrm{NO}_{3}^{-}-\mathrm{SO}_{4}^{2-}-\mathrm{H}_{2} \mathrm{O}$ at 298.15 K, Aerosol Sci. Tech., 27, 345-366, 1997.

Cruz, C. N. and Pandis, S. N.: Deliquescence and Hygroscopic Growth of Mixed Inorganic-Organic Atmospheric Aerosol, Environ. Sci. Technol., 34, 4313-4319, 2000.

Dai, Q. and Salmeron, M.: Adsorption of Water on $\mathrm{NaCl}$ (100) Surfaces: Role of Atomic Steps, J. Phys. Chem. B, 101, 19941998, 1997.

Debenedetti, P. G. and Stillinger, F. H.: Supercooled liquids and the glass transition, Nature, 410, 259-267, 2001.

De Haan, D. O., Brauers, T., Oum, K., Stutz, J., Nordmeyer, T., and Finlayson-Pitts, B. J.: Heterogeneous chemistry in the troposphere: experimental approaches and applications to the chemistry of sea salt particles, Intern. Rev. Phys. Chem., 18, 343-385, 1999.

Frank, G. A.: Measurement Analysis of Glass Transition Temperature for sucrose an Trehalose Aqueous Solutions, J. Phys. Chem. Ref. Data., 36(4), 1279-1285, 2007.

Franks, F.: Solid aqueous solutions, Pure Appl. Chem., 65(12), 2527-2537, 1993.

Graham, B., Mayol-Bracero, O. L., Guyon, P., Roberts, G. C., Decesari, S., Cristina Facchini, M. C., Artaxo, P., Maenhaut, W., Köll, P., and Andreae, M. O.: Water-soluble organic com- 
pounds in biomass burning aerosols over Amazonia 1. Characterization by NMR and GC-MS, J. Geophys. Res., 107(D20), 8047, doi:10.1029/2001JD000336, 2002.

Halbout, J.-M. and Tang, C. L.: Phase-Matched Second-Harmonic Generation in Sucrose, IEEE Journal Of Quantum Electronics, QE-18, 410-415, 1982.

Hanford, K. L., Mitchem, L., Reid, J. P., Clegg, S. L., Topping, D. O., and McFiggans, G. B.: Comparative Thermodynamic Studies of Aqueous Glutaric Acid, Ammonium Sulfate and Sodium Chloride Aerosol at High Humidity, J. Phys., Chem. A., 112, 9413-9422, 2008.

Hargreaves, G., Kwamena, N.-O. A., Zhang, Y. H., Butler, J. R., Rushworth, S., Clegg, S. L., and Reid, J. P.: Measurements of the Equilibrium Sizes of Supersaturated Aqueous Sodium Chloride Droplets at Low Relative Humidity Using Aerosol Optical Tweezers and an Electrodynamic Balance, J. Phys. Chem. A., 114, 1806-1815, 2010.

Haynes, W. M. (ed.): Physical Constants of Organic Compounds, in CRC Handbook of Chemistry and Physics, 91st Edition (Internet Version 2011), CRC Press/Taylor and Francis, Boca Raton, FL, USA, 2011.

Haywood, J. and Boucher, O.: Estimates of the direct and indirect radiative forcing due to tropospheric aerosols: A review, Rev. Geophys., 38, 513-543, 2000.

He, X., Fowler, A. and Toner, M.: Water activity and mobility in solutions of glycerol and small molecular weight sugars: Implication for cryo- and lyopreservation, J. Appl. Phys., 100, 074702, 2006.

Henzler, M., Stock, A., and Böl, M.: Adsorption on Ordered Surfaces on Ionic Solids and Thin Films, Springer, Berlin, Germany, 1993.

Hoffman, R. C., Laskin, A., and Finlayson-Pitts, BJ.: Sodium nitrate particles: physical and chemical properties during hydration and dehydration, and implications for aged sea salt aerosols, J. Aerosol Sci., 35, 869-887, 2004.

Hsu, C.-L., Heldman, D. R., Taylor, T. A., and Kramer, H. L.: Influence of cooling rate on glass transition temperature of sucrose solutions and rice starch gel, J. Food Sci., 68(6), 1970-1975, 2003.

Huffman, J. A., Docherty, K. S., Aiken, A. C., Cubison, M. J., UIbrich, I. M., DeCarlo, P. F., Sueper, D., Jayne, J. T., Worsnop, D. R., Ziemann, P. J., and Jimenez, J. L.: Chemically-resolved aerosol volatility measurements from two megacity field studies, Atmos. Chem. Phys., 9, 7161-7182, doi:10.5194/acp-9-71612009, 2009.

International Organization of Legal Metrology, Refractometers for the measurement of the sugar content of fruit juices, International Recommendation OIML R 108, available online at: http://www. oiml.org/publications/R/R108-e93.pdf, 1993.

Kolb, C. E., Cox, R. A., Abbatt, J. P. D., Ammann, M., Davis, E. J., Donaldson, D. J., Garrett, B. C., George, C., Griffiths, P. T., Hanson, D. R., Kulmala, M., McFiggans, G., Pöschl, U., Riipinen, I., Rossi, M. J., Rudich, Y., Wagner, P. E., Winkler, P. M., Worsnop, D. R., and O' Dowd, C. D.: An overview of current issues in the uptake of atmospheric trace gases by aerosols and clouds, Atmos. Chem. Phys., 10, 10561-10605, doi:10.5194/acp-10-10561-2010, 2010.

Koster, K. L.: Glass formation and desiccation tolerance in seeds, Plant Physiol. 96, 302-304, 1991.

Kwamena, N.-O. A., Buajarern, J., and Reid, J. P.: Equilib- rium Morphology of Mixed Organic/Inorganic/Aqueous Aerosol Droplets: Investigating the Effects of Relative Humidity and Surfactants, J. Phys. Chem. A., 114, 5787-5795, 2010.

Labuza, T. B.: Moisture Sorption: Practical Aspects of Isotherm Measurement and Use, American Association of Cereal Chemists, St. Paul, MN, USA, 1984.

Le Meste M., Champion, D., Roudaut, G., Blond, G., and Simatos, D.: Glass transition and food technology: A critical appraisal, J. Food. Sci., 67, 2444-2458, 2002.

Lerici, C. R., Piva, M., and Rosa, M. D.: Water activity and freezing point depression of aqueous solutions and liquid foods, J. Food Sci., 48, 1667-1669, 1983.

Lightstone, J. M., Onasch, T. B., and Imre, D.: Deliquescence, Efflorescence, and Water Activity in Ammonium Nitrate and Mixed Ammonium Nitrate/Succinic Acid Microparticles. J. Phys. Chem. A., 104, 9337-9346, 2000.

Liu, Y. J., Zhu, T. Zhao, D. F., and Zhang, Z. F.: Investigation of the hygroscopic properties of $\mathrm{Ca}\left(\mathrm{NO}_{3}\right)_{2}$ and internally mixed $\mathrm{Ca}\left(\mathrm{NO}_{3}\right)_{2} / \mathrm{CaCO}_{3}$ particles by micro-Raman spectrometry, Atmos. Chem. Phys., 8, 7205-7215, doi:10.5194/acp-8-7205-2008, 2008.

Lohmann, U. and Feichter, J.: Global indirect aerosol effects: a review, Atmos. Chem. Phys., 5, 715-737, doi:10.5194/acp-5-7152005, 2005.

MacKenzie, A. P., Derbyshire, W., and Reid, D. S.: NonEquilibrium Freezing Behaviour of Aqueous Systems, Phil. Trans. R. Soc. Lnd. B, 278, 167-189, 1977.

Marshak, R. E.: Effect of radiation on shock wave behaviour, Physics of Fluids, 1, 24-29, 1958.

Martin, S. T.: Transitions of Aqueous Atmospheric Particles, Chem. Rev., 100, 3403-3454, 2000.

McGraw, R. and Lewis, E. R.: Deliquescence and efflorescence of small particles, J. Chem. Phys., 131(19), 194705, 2009.

Mikhailov, E., Vlasenko, S., Martin, S. T., Koop, T., and Pöschl, U.: Amorphous and crystalline aerosol particles interacting with water vapor: conceptual framework and experimental evidence for restructuring, phase transitions and kinetic limitations, Atmos. Chem. Phys., 9, 9491-9522, doi:10.5194/acp-9-9491-2009, 2009.

Miles, R. E. H., Knox, K. J., Reid, J. P., Laurain, A. M. C., and Mitchem, L.: Measurements of Mass and Heat Transfer at a Liquid Water Surface during Condensation or Evaporation of a Subnanometer Thickness Layer of Water, Phys. Rev. Lett., 105, 116101, 2010.

Mitchem, L., Buajarern, J., Hopkins, R. J., Ward, A. D., Gilham, R. J. J., Johnston, R. L., and Reid, J. P.: The spectroscopy of growing and evaporating water droplets: Exploring the variation in equilibrium droplet size with relative humidity, J. Phys. Chem. A 110, 8116-8125, 2006.

Mitchem, L. and Reid, J. P.: Optical manipulation and characterization of aerosol particles using a single-beam gradient force optical trap, Chem. Soc. Rev., 37, 756-769, 2008.

Mogensen, J. M., Nielsen, K. F., Samson, R. A., Frisvad, J. C. and Thrane, U.: Effect of temperature and water activity on the production of fumonisins by Aspergillus nigeer and different Fusarium species, BMC Microbiology., 9, p. 281, 2009.

Murray, B. J.: Inhibition of ice crystallization in highly viscous aqueous organic acid droplets, Atmos. Chem. Phys., 8, 54235433, doi:10.5194/acp-8-5423-2008, 2008. 
Murray, B. J., Wilson, T. W., Dobbie, S., Cui, Z. Q., Al-Jumur, S. M. R. K., Mohler, O., Schnaiter, M., Wagner, R., Benz, S., Niemand, M., Saathoff, H., Ebert, V., Wagner, S., and Karcher, B.: Heterogeneous nucleation of ice particles on glassy aerosols under cirrus conditions, Nat. Geosci., 3, 233-237, 2010.

Norrish, R. S.: An equation for the activity coefficients and equilibrium relative humidities of water in confectionery syrups, J. Food Technol., 1, 25-39, 1966.

Orford, P. D., Parker, R., and Ring, S. G.: Aspects of the glass transition behavior of mixtures of carbohydrates of low molecular weight, Carhohydrol. Res., 196, 11-18, 1990.

Peng, C., Chain, M. N., and Chan, C. K.: The hygroscopic properties of dicarboxylic and multifunctional acids: measurements and UNIFAC predictions, Environ. Sci. Tech., 35, 4495-4501, 2001.

Peng, C., Chow, A. H. L., and Chan, C. K.: Hygroscopic Study of Glucose, Citric Acid, and Sorbitol Using and Electrodynamic Balance: Comparison with UNIFAC Predictions, Aerosol Sci. Technol. Technol., 35, 753-758, 2001.

Pope, F. P., Dennis-Smither, B. J., Griffiths, P. T., Clegg, S. L., and Cox, R. A.: Studies of Single Aerosol Particles Containing Malonic Acid, Glutaric Acid, and Their Mixtures with Sodium Chloride. I. Hygroscopic Growth, J. Phys. Chem. A., 114, 5335-5341, 2010a.

Pope, F. P., Tong, H. J., Dennis-Smither, B. J., Griffiths, P. T., Clegg, S. L., Reid, J. P., and Cox, R. A.: Studies of Single Aerosol Particles Containing Malonic Acid, Glutaric Acid, and Their Mixtures with Sodium Chloride. II. Liquid-State Vapor Pressures of the Acids, J. Phys. Chem. A., 114, 10156-10165, 2010b.

Pósfai, M. and Buseck, P. R.: Nature and Climate Effects of Individual Tropospheric Aerosol Particles, Annu. Rev. Earth Planet. Sci., 38, 17-43, 2010.

Prenni, A. J., DeMott, P. J., Kreidenweis, S. M., and Sherman, D. E.: The Effects of Low Molecular Weight Dicarboxylic Acids on Cloud Formation, J. Phys. Chem. A., 105, 11240-11248, 2001.

Rabinowitz, J. D., Lloyd, P. M., Munzar, P., Myers, D. J., Cross, S., Damani, R., Quintana, R., Spyker, D. A., Soni, P., and Cassella, J. V.: Ultra-Fast Absorption of Amorphous Pure Drug Aerosols Via Deep Lung Inhalation, J. Pharm. Sci., 95(11), 2438-2451, 2006.

Ravishankara, A. R.: Heterogeneous and Multiphase Chemistry in the Troposphere, Science, 276, 1058-1065, 1997.

Reinhardt, A., Emmenegger, C., Gerrits, B., Panse, C., Dommen, J., Baltensperger, U., Zenobi, R., and Kalberer, M.: Ultrahigh Mass Resolution and Accurate Mass Measurements as a Tool to Characterize Oligomers in Secondary Organic Aerosols, Anal. Chem., 79, 4074-4082, 2007.

Robinson, R. A. and Stokes, R. H.: Electrolyte Solutions, 2nd ed., Butterworths, London, UK, 1965.

Roos, Y.: Melting and glass transitions of low molecular weight carbohydrates, Carbohydr. Res. 238, 39-48, 1993.

Roos, Y.: Glass Transition Temperature and Its Relevance in Food Processing, Annu. Rev. Food Sci. Technol., 1, 469-496, 2010.

Roos, Y. and Karel, M.: Water and Molecular Weight Effects on Glass transitions in Amorphus Carbohydrates and Carbohydrate solutions, J. Food Sci., 56(6), 1676-1681, 1991.

Rüegg, M. and Blanc, B.: The water activity of honey and related sugar solutions, Lebensm. Wiss. Technol., 14, 1-6, 1981.

Scatchard, G., Hamer, W. J. and Wood, E.: Isotonic solutions. I.
The chemical potential of water in aqueous solutions of sodium chloride, potassium chloride, sulphuric acid, sucrose, urea and glycerol at $25^{\circ}$ C, J. Am. Chem. Soc., 60, 3061-3070, 1938.

Shindo, H., Ohashi, M., Tateishi, O., and Seo, A.: Atomic force microscopic observation of step movements on $\mathrm{NaCl}(001)$ and $\mathrm{NaF}(001)$ with the help of adsorbed water, J. Chem. Soc., Faraday Trans., 93(6), 1169-1174, 1997.

Starzak, M. and Peacock S. D.: Water activity coefficient in aqueous solutions of sucrose-a comprehensive data analysis, Zuckerind., 122, 380-387, 1997.

Sun, W. Q., Leopold, A. C., Crowe, L. M. and Crowe, J. H.: Stability of Dry Liposomes in Sugar Glasses, Biophys. J., 70, 17691776, 1996.

Tang, I. N. and Fung, K. K.: Hydration and Raman scattering studies of levitated microparticles: $\mathrm{Ba}\left(\mathrm{NO}_{3}\right)_{2}, \mathrm{Sr}\left(\mathrm{NO}_{3}\right)_{2}$, and $\mathrm{Ca}$ $\left(\mathrm{NO}_{3}\right)_{2}$, J. Chem. Phys., 106, 1653-1660, 1997.

Tang, I. N. and Munkelwitz, H. R.: Composition and temperature dependence of the deliquescence properties of hygroscopic aerosols, Atmos. Environ., 27A(4), 467-473, 1993.

Tang, I. N. and Munkelwitz, H. R.: Aerosol Phase Transformation and Growth in the Atmosphere, J. Appl. Meteorol., 33, 791-796, 1994.

Topping, D. O., McFiggans, G. B., and Coe, H.: A curved multicomponent aerosol hygroscopicity model framework: Part 2Including organic compounds, Atmos. Chem. Phys., 5, 1223 1242, doi:10.5194/acp-5-1223-2005, 2005.

Virtanen, A., Joutsensaari, J., Koop, T., Kannosto, J., Yli-Pirilä, P., Leskinen, J., Mäkelä, J. M., Holopainen, J. K., Pöschl, U., Kulmala, M., Worsnop, D. R., and Laaksonen, A.: An amorphous solid state of biogenic secondary organic aerosol particles, Nature, 467, 824-827, 2010.

Wang, G., Kawamura, K., and Lee, M.: Comparison of organic compositions in dust storm and normal aerosol samples collected at Gosan, Jeju Island, during spring 2005, Atmos. Environ., 43, 219-227, 2009.

Wills, J. B., Knox, K. J., and Reid, J. P.: Optical control and characterization of aerosol, Chem. Phys. Lett., 481, 153-165, 2009.

Wise, M. E., Martin, S. T., Russell, L. M., and Buseck, P. R.: Water Uptake by $\mathrm{NaCl}$ Particles Prior to Deliquescence and the Phase Rule, Aerosol Sci. Technol., 42, 281-294, 2008.

Yttri, K. E., Dye, C., and Kiss, G.: Ambient serosol concentrations of sugars and sugar-alcohols at four different sites in Norway, Atmos. Chem. Phys., 7, 4267-4279, 2007, http://www.atmos-chem-phys.net/7/4267/2007/.

Yu, H., Kaufman, Y. J., Chin, M., Feingold, G., Remer, L. A., Anderson, T. L., Balkanski, Y., Bellouin, N., Boucher, O., Christopher, S., DeCola, P., Kahn, R., Koch, D., Loeb, N., Reddy, M. S., Schulz, M., Takemura, T. and Zhou, M.: A review of measurement-based assessments of the aerosol direct radiative effect and forcing, Atmos. Chem. Phys., 6, 613-666, doi:10.5194/acp-6-613-2006, 2006.

Zardini, A. A., Sjogren, S., Marcolli, C., Krieger, U. K., Gysel, M., Weingartner, E., Baltensperger, U., and Peter, T.: A combined particle trap/HTDMA hygroscopicity study of mixed inorganic/organic aerosol particles, Atmos. Chem. Phys., 8, 55895601, doi:10.5194/acp-8-5589-2008, 2008.

Zhang, Y. H., Choi, M. Y., and Chan, C. K.: Relating Hygroscopic properties of Magnesium Nitrates to the Formation of Contact Ion Pairs, J. Phys. Chem. A., 108, 1712-1718, 2004. 
Zieger, P., Fierz-Schmidhauser, R., Gysel, M., Ström, J., Henne, S., Yttri, K. E., Baltensperger, U. and Weingartner, E.: Effects of relative humidity on aerosol light scattering in the Arctic, Atmos. Chem. Phys., 10, 3875-3890, doi:10.5194/acp-10-38752010, 2010.

Zobrist, B., Marcolli, C., Pedernera, D. A. and Koop, T.: Do atmospheric aerosols form glasses?, Atmos. Chem. Phys., 8, 52215244, doi:10.5194/acp-8-5221-2008, 2008.
Zobrist, B., Soonsin, V., Luo, B. P., Krieger, U. K., Marcolli, C., Peter T., and Koop, T.: Ultra-slow water diffusion in aqueous sucrose glasses, Phys. Chem. Chem. Phys., 13, 3514-3526, 2011. 